\title{
DESCRIÇÃO MICROSCÓPICA DOS OVÁRIOS DE Callinectes ornatus (Crustacea: Brachyura) DO LITORAL SUL DO ESPÍRITO SANTO
}

\author{
Marina Lopes Marinho ${ }^{1}$ \\ Jamily Almeida Fontoura ${ }^{2}$ \\ Tugstênio Lima de Souza ${ }^{3}$ \\ Adriane Araújo Braga ${ }^{4}$ \\ Erika Takagi Nunes ${ }^{5}$
}

Resumo: O presente estudo visou caracterizar a morfologia microscópica das gônadas femininas de siris Callinectes ornatus, coletados no litoral de Anchieta/ES, entre outubro de 2013 e outubro de 2014. Os animais foram triados e as fêmeas tiveram seu sistema reprodutor dissecado e submetido à rotina histológica para a análise sob microscopia de luz. Ao longo do processo da maturação foi notado que as células menos desenvolvidas, de oogônias à oócitos II, o citoplasma é altamente basófilo. Já os oócitos IIIIV possuem um aumento de acidofilia plasmática, caracterizado pela incorporação de vitelo, provavelmente de origem exógena, e amadurecimento destas células. Quando observado microscopicamente, os tipos celulares encontrados nas gônadas permitiram caracterizar as fases de desenvolvimento gonadal. Sendo imaturas as que apresentaram oogônias e oócitos l; as rudimentares, oócitos II; aquelas em desenvolvimento, oócitos III; as desenvolvidas, oócitos IV; e aquelas no estágio esgotado, oócitos sendo absorvidos pelo ovário.

Palavras-chave: Reprodução; Histologia; Ovócito; Siri; Ovogênese.

\footnotetext{
1 Universidade Federal do Espirito Santo, Brasil. E-mail: marinalopesmarinho@gmail.com.

2 Universidade Federal do Espirito Santo, Brasil. E-mail: jamilyfontoura@gmail.com.

3 Universidade Federal do Espirito Santo, Brasil. E-mail: tugstenio94@hotmail.com.

${ }^{4}$ Universidade Federal do Espirito Santo, Brasil. E-mail: dricrab@yahoo.com.br.

${ }^{5}$ Universidade Federal do Espirito Santo, Brasil. E-mail: erikatnunes@gmail.com.
} 